\title{
CSResearch Square \\ Orofacial Manifestations of Chronic Renal Failure at Ahmed Gasim Hospital and Dr. Salma Center for Kidney Diseases. Khartoum
}

Arwa Mohamed Abouna ( $\sim$ arwaabouna@gmail.com )

Research article

Keywords: chronic renal failure, orofacial manifestations, xerostomia, Hemodialysis

Posted Date: June 1st, 2020

DOI: https://doi.org/10.21203/rs.3.rs-30271/v1

License: (c) (i) This work is licensed under a Creative Commons Attribution 4.0 International License.

Read Full License 


\section{Abstract}

Background: Chronic renal failure is defined as kidney damage, or a reduction in the glomerular filtration rate, for three or more months. Few studies were performed regarding the oral health status of chronic renal failure patients in Sudan.

Objective: Study aims to investigate the pattern of orofacial manifestations in patients with chronic renal failure in Sudan and how the disease affecting their oral health.

Methods: The present study is a hospital based study conducted at Dr. Salma Center for Treatment of Kidney diseases, University of Khartoum, Sudan and Department of Nephrology at Ahmed Gasim Hospital for Heart Surgery and Kidney Diseases -khartoum Bahri, Sudan, between January to June 2019. Two hundred and twenty six patients participated in the study. The frequency and pattern of orofacial manifestations among those patient in addition to presence of additional systemic diseases ,duration of dialysis and mean levels of urea ,creatinine and hemoglobin were all investigated.

Results: Oral lesions were present in 103 out of 226 (45.6\%) patients with chronic renal failure .Xerostomia was the most manifestation encountered [145 (64.2\%)], followed by orofacial abcess, ulcers and candidiasis. Hypertention was the commonest systemic disease encountered .No significant difference was found regarding the orofacial manifestations with duration of dialysis , urea ,hemoglobin and creatinine mean levels.

Conclusions: Prevalence of orofacial manifestations was significantly high among CRF patients .Xerostomia was the main complaint recognized. The findings of the present study emphasize the importance of dental practitioners in monitoring the oral health of patients with chronic renal faliure, and the need for regular clinical examinations to ensure early diagnosis and management of patients.

\section{Background}

Chronic renal failure is defined as kidney damage, or a reduction in the glomerular filtration rate, for three or more months. The disease is classified as chronic and

Acute according to the clinical manifestation and dialysis is used to mechanically wash out waste products of the metabolism ${ }^{[1,2]}$.

Chronic renal failure can cause oral manifestations like any other systemic disease but can be reversed after kidney transplant ${ }^{[3]}$.Viral infections, leukoplakia , metallic test, burning sensations, uremic stomatitis and Xerostomia which was the most prevalence by $73.2 \%$ were recognized as oral lesions among chronic renal failure patients possibly due to disruption of the salivary gland and lung perfusion leading to mouth breathing $[2,4,5,6]$. 
In Sudan new cases of chronic renal failure patients is $70-140$ per million inhabitant/ year ${ }^{[7]}$ raising the need to more studies about the oral health among those patients.

\section{Objective}

In Sudan many patients of chronic renal failure going through hemodialysis and some of them had a kidney transplant but the condition of their oral health never discussed before. This study aims to investigate the orofacial manifestations in patients with renal failure and how the disease affecting their oral health taking in account the duration of renal failure and associated viral and chronic systemic diseases

\section{Methodology}

The present study is a hospital based study conducted at Dr. Salma Center for Treatment of Kidney diseases, University of Khartoum, Sudan and Department of Nephrology at Ahmed Gasim Hospital for Heart Surgery and Kidney Diseases - Khartoum Bahri, Sudan. Between January to June 2019. Two hundred and twenty six patients participated in the study. Patients under antibiotics' therapy during the last three months, Individuals who were tobacco smokers, Dentures wearers, or received radiotherapy or Chemotherapy were excluded, Caries and periodontal lesions were exempted as they are out of the scope of this study. Two hundred and twenty six patients(124 males and 102 females) above 18 years interviewed and examined to detect frequency and pattern of orofacial manifestations among patients with renal failure. The presence of additional systemic diseases, duration of dialysis and mean levels of urea, creatinine and hemoglobin were all investigated.

Oral mucosa assessment was based on the WHO Guide ${ }^{[8]}$ and Xerostomia was assessed by American Dental Association criteria ${ }^{[9]}$.

\section{Ethical considerations:}

Ethical approval was obtained from the Research Committee University of Khartoum faculty of dentistry, Research Committee of the Ministry of health and Written informed consent was taken from each patient.

\section{Results}

\section{Demographic data}

Two hundred and twenty six subjects participated in the study 124(55\%) males and 102 (45\%) females. The age of participants ranged between 18 to 86 years with a mean age of (46.5) years. 


\section{Prevalence of orofacial manifestations}

Orofacial manifestations in chronic renal failure patients were investigated and categorized depending on the order of frequency as follows: no manifestations [123(54.4)] , Ulcers [41 (18.1\%)], Abscess [23 (10\%)], Petechiae hemorrhage [20(8.8\%)], Burning sensation [6(2.6)] Leukoplakia [2(.9\%)], Lichn planus [1(.4)] and Candidisis[10(4.4)].Table (1).

Xerostomia which was assessed by American Dental Association criteria [9]. was found among 145patients $(64.2 \%), 78$ were males and 67 were females, The association between xerostomia and other manifestations is illustrated in table (2).

Table 1

frequency and percentage of oral mucosal lesions

\begin{tabular}{|c|c|}
\hline Oral mucosal lesions & N (\%) \\
\hline No manifestations & $123(54.4)$ \\
\hline Abscess & $23 \quad(10)$ \\
\hline Petechia and hemorrhage & $20(8.8)$ \\
\hline Ulcers & $41(18.1)$ \\
\hline Candidisis & $10(4.4)$ \\
\hline Burning sensation & $6 \quad(2.6)$ \\
\hline Leukoplakia & $2 \quad(.9)$ \\
\hline Lichn planus & $1 \quad(.4)$ \\
\hline Total & $226(100)$ \\
\hline
\end{tabular}


Table 2

Association between oral mucosal lesions and xerostomia

\begin{tabular}{|lll|}
\hline Oral mucosal lesions & \multicolumn{2}{r|}{ Xerostomia N(\%) } \\
\cline { 2 - 3 } & Negative & Positive \\
\hline No oral lesions & $63(27.8)$ & $60(26.5)$ \\
\hline Leukoplakia & $0(0)$ & $2(1)$ \\
\hline Ulceration & $8(3.4)$ & $33(14.6)$ \\
\hline Candidisis & $0(0)$ & $1(.4)$ \\
\hline Abcess & $1(.4)$ & $9(4)$ \\
\hline Petechiae hamorrhage & $5(2.2)$ & $22(9.7)$ \\
\hline Burning sensation & $2(1)$ & $3(1.4)$ \\
\hline Total & $81(35.8)$ & $145(64.2)$ \\
\hline
\end{tabular}

There is highly significant association $(p=.05)$

\section{Association between systemic diseases and oral manifestations}

Medical history of CRF patients was taken into account but no statistical significant was found with the presence of oral lesions $\mathrm{P}>0.05$. Hypertension was the most recognized systemic disease among CRF patients who suffered from abscess, ulcers, petechiae and hemorrhage and Candida infections. Diabetic patients showed ulcers ,abscess, petechiae and hemorrhage and burning sensations.

Table 3

prevalence of oral lesions among CRF patients and it is association with their systemic diseases.

\begin{tabular}{|llll|}
\hline \multirow{2}{*}{ Systemic disease } & \multicolumn{2}{c|}{ Oral lesion } & \\
\cline { 2 - 3 } & Absent & Present & N(\%) \\
\hline Hypertension & 43 & 32 & $75(33.2)$ \\
\hline diabetes & 6 & 14 & $20(9.1)$ \\
\hline HBV & 3 & 2 & $5(2.2)$ \\
\hline HCV & 4 & 0 & $4(1.7)$ \\
\hline Cardiac disease & 2 & 0 & $2(.8)$ \\
\hline
\end{tabular}




\section{Association between oral mucosal lesions and duration of dialysis}

Patients were categorized depending on the duration of the dialysis into 3 categories, 5 years or less:116 patients (51.3\%) the second group : more than 5 but less than 10 years which accounts for 43 patients (19\%) the last group : more than 10 years: 67 patients (29.6\%). No statistically significant difference was noted between the presence of manifestations and duration of dialysis. As shown in Table (4).

Table (4):

Table 4

Association between oral mucosal lesions and duration of dialysis

\begin{tabular}{|c|c|c|c|}
\hline Duration & Positive oral finding $\mathrm{N}(\%)$ & Negative oral finding $N(\%)$ & Total N (\%) \\
\hline$<=5$ years & $48(21.2)$ & $68(30.1)$ & $116(51.3)$ \\
\hline $5-9$ years & $21(9.4)$ & $22(9.7)$ & $43(19.1)$ \\
\hline$>=10$ years & $34(15)$ & $33(14.6)$ & $67(29.6)$ \\
\hline Total N (\%) & $103(45.6)$ & $123(54.4)$ & $226(100)$ \\
\hline
\end{tabular}

Chi squire test performed, $(p=.05) P$ value is not significant

\section{Associations between Hemoglobin, urea, creatinine levels and oral mucosal lesions}

The mean blood urea concentration in Chronic renal failure patients with oral lesion $(56.3 \mathrm{mmol} / \mathrm{L})$ was compared with those without oral lesions

$(46 \mathrm{mmol} / \mathrm{L})$ and was not statistically significant $(P>0.05)$.

Also there was no significant difference $(P>0.05)$ regarding the presence of orofacial manifestations and levels of Hemoglobin, urea and creatinine. Table (5). 
Table 5

Associations between Hemoglobin, urea, creatinine levels and oral mucosal lesions

\begin{tabular}{|c|c|c|c|c|c|}
\hline & & Pos & tive finding of oral lesion & Negative finding of oral lesion & Total \\
\hline \multirow[b]{2}{*}{$\mathrm{Hb}$} & Normal & & $(28.3 \%)$ & 70 (30.9 \%) & 226 \\
\hline & Low & 40 & $(17.6 \%)$ & $53(23.4 \%)$ & $100 \%$ \\
\hline \multirow[t]{2}{*}{ urea } & High & 59 & $(26.1 \%)$ & $47(20.8 \%)$ & 226 \\
\hline & Low & 44 & (19.5\%) & $76(33.6 \%)$ & $100 \%$ \\
\hline \multirow[t]{2}{*}{ creatinine } & High & 46 & $(20.3 \%)$ & $61(27.1 \%)$ & 226 \\
\hline & Low & 57 & $(25.2 \%)$ & $62(27.4 \%)$ & 100 \\
\hline
\end{tabular}

Chi squire test performed, $P$ value is not significant $(p=.05)$

Discussion

Literature review shows few studies on oral health status of patients of CRF. The objectives of this study was to investigate the oral manifestation of CRF in a sample of hemodialysis patients in two different centers, two hundred and twenty six (226) subjects participated in this study 124 (55\%) males and 102 $(45 \%)$ Females, these finding were similar to Mansourian et al . ${ }^{[10]}$ Who reported a predominant of male gender 93 patients (59 male, 63.4\%) and ( 34 female,36.6\%).

The age of participants ranged between 18 to 86 years with a mean age of (46.5) years this finding in accordance with Elijah et al. ${ }^{[11]}$, who mentioned an average age ( 47.73 ) years and akanksha et al. [ ${ }^{12]}$ with a mean age (43.24 years) .

With regard to pattern of orofacial manifestations, the current study

representing similarity to many previous studies, where xerostomia was the most frequent orofacial manifestation observed (64. 2\%), followed by Ulcers [41 (18.1\%)], Abscess [23 (10\%)], Petechiae and hemorrhage [20(8.8\%)], Burning sensation[6(2.6)], Leukoplakia [2(.9\%)], Lichn planus[1(.4\%)]and Candidiasis [10(4.4\%)]. These findings were consistent with the report of Kuravatti et al. and Patil et al., who found that Xerostomia or dry mouth, is a frequent complaint among dialysis patients $[2,6]$.

Hypertension was the most recognized systemic disease among CRF patients 75 (33.2\%) from the total sample and antihypertensive therapy which may also complicate the oral finding and its management Akar et al. observed a correlations between oral manifestations in CRF patients especially xerostomia and antihypertensive drugs [13].

No significant relation between oral mucosal lesions and duration of dialysis found in this study, which is corresponding with Bots et al. study ${ }^{[14]}$ and Cristina et al. study ${ }^{[15]}$. 
In Cerveró et al. study, The severity of oral manifestations are related to patients age at the time of presentation of renal failure, and the duration of dialysis ${ }^{[16] .}$

There is a significant relationship between high urea level and xerostomia in patients under dialysis, but no significant relation with oral mucosal lesion in the current study. These findings are contrary to the findings of Patil et al. , study who found The diminished function of the kidneys results in an increase in the levels of urea in the blood and also in the saliva which lead to burning sensation ${ }^{[6]}$, serum urea and creatinine value increases, salivary urea and creatinine value also increases and vice versa ${ }^{[17]}$.

In a study by Klassen et al. high lighted the presence of dysgeusia, uremic fetor bad taste and odor also, the presence of urease-splitting oral organisms, which metabolize urea (present in high levels in these patients) and thus elaborate ammonia ${ }^{[18]}$.

Silvia et al ${ }^{[4]}$ reported the relationship between the urea level and halitosis, unpleasant metallic taste no such manifestations were found in this study.

\section{Conclusion}

In this study, patients with CRF showed high prevalence of orofacial manifestations and a significant percentage of xerostomia, no direct correlation with the chronic renal failure, but with obvious relation with other systemic diseases especially hypertension. Data emphasize the importance of dentists in monitoring the oral health of patients with chronic renal faliure, and regular clinical examinations to ensure early diagnosis and management of patients.

\section{List Of Abbreviations}

CRF: Chronic Renal Failure

$\mathrm{Hb}:$ Hemoglobin

\section{Declarations}

\section{Ethical approval}

Ethical approval was obtained from Research Committee University of Khartoum - faculty of dentistry. Ethical clearance was obtained from the Research Committee of the Ministry of health.

Written consent was obtained from the patients before conducting the research.

\section{Patients' Consent}

Title : Orofacial Manifestations of Chronic Renal Failure at Ahmed Gasim 
Hospital and Dr.Salma Center for treatment of Kidney Diseases.

\section{Purpose of the research:}

To asses the orofacial manifestation of chronic renal failure among Sudanese patients .

\section{Conflict of interest:}

This research will be done by Dr. Arwa Mohamed in partial fulfillment for the requirement of the degree of Master Degree in OMFs.

\section{Confidentiality:}

The information about you will be kept confidential and it will not be disclosed to any one apart from the researcher. All data will be kept in a secure place and it will be destroyed after the research is completed.

\section{Potential Benefits:}

If you participate in this research, you will benefit from investigations also your participation may help others in the future by the study results.

\section{Potential Risks:}

There is no risk from Participation in this study.

\section{Contact Person:}

If you have any questions you may ask them now or later, even after the study has started.

If you have any inquiries please call Dr. Arwa Mohamed at

University of Khartoum, Faculty of Denristry, OMFsDepartment, contact no.

00249910505335.

Email: arwaabouna@gmail.com

Participation in this study is voluntary. You will suffer no penalty or loss of any benefits to which you are otherwise entitled should you decide not to participate. Significant new finding developed during the course of the research study, which might be reasonably expected to affect you your willingness to continue to participate in the research study, will be provided to you.

CONCENT: I acknowledge:

1. I had read and had explained to me the above information regarding this research study.

2. I had an opportunity ask questions and that all my questions have been answered to my satisfaction.

3. My participation in this research is voluntary.

4. I may withdraw from the study at any time without affecting my ability to receive alternative medical care available/

5. I fully understand that there may not be any direct medical benefit 
to me by participating in this research study.

6 . I will be given a signed copy of this consent.

Patient signature

Date.

Consent for publication : Not applicable.

Availability of data and materials : the datasets used and/or analysed during the current study are available from the corresponding auther on reasonable request.

Competing interests : the authors declare that they have no competing interests.

Funding : personal funding.

\section{Authors'contributions}

Arwa Mohamed Abubakr Abouna was involved in conception of the idea, assessment of patients with chronic renal failure, drafting the manuscript and in data collection.

Yousif Osman Yousif involved in conception of the idea, participated in the study design, supervised data collection , reviewed the manuscript and gave the final approval of the version to be sent for publication.

\section{Acknowledgement}

Not applicable

\section{References}

1. Scully C. Medical Problems in Dentistry E-Book: Elsevier Health Sciences; 2010.

2.

Kuravatti S, David MP, Indira A. Oral manifestations of chronic kidney disease-an overview. Int JContemp Med Res. 2016;3:1149-52.

3. Mozaffari PM, Amirchaghmaghi M, Mortazavi H. Oral manifestations of renal patients before and after transplantation: a review of literature. DJH. 2009;1(1):1-6.

4. Álamo SM, Esteve CG, Pérez MGS. Dental considerations for the patient with renal disease. J ClinExp Dent. 2011;3(2):112-9.

5. Hernández C. Oral disorders in patients with chronic renal failure. Narrative review. Journal Oral Of Research. 2016;5(1):27-34.

6. Patil S, Khaandelwal S, Doni B, Rahuman F, Kaswan S. Oral manifestations in chronic renal failure patients attending two hospitals in North Karnataka, India. Oral Health Dent Manag. 2012;11(3):1006. 
7. Banaga AS, Mohammed EB, Siddig RM, Salama DE, Elbashir SB, Khojali MO, et al. Causes of end stage renal failure among haemodialysis patients in Khartoum State/Sudan. BMC research notes. 2015;8(1):502.

8. Organization WHO. Oral health surveys: basic methods: World Health Organization; 2013.

9. Plemons JM, Al-Hashimi I, Marek CL. Managing xerostomia and salivary gland hypofunction: executive summary of a report from the American Dental Association Council on Scientific Affairs. The Journal of the American Dental Association. 2014;145(8):867-73.

10. Mansourian A, Manouchehri A, Shirazian S, Moslemi E, Haghpanah G. Comparison of oral lesion prevalence between renal transplant patients and dialysis patients. Journal of dentistry (Tehran, Iran). 2013;10(6):487.

11. Oyetola EO, Owotade FJ, Agbelusi GA, Fatusi OA, Sanusi AA. Oral findings in chronic kidney disease: implications for management in developing countries. BMC Oral Health. 2015;15(1):24.

12. Yadav A, Deepak U, Misra N, Kumar GC, Kaur A. Oral manifestations in renal failure patients undergoing Dialysis. International Journal of Medical Science and Public Health. 2015;4(7):1015.

13. Akar H, Akar GC, Carrero JJ, Stenvinkel P, Lindholm B. Systemic consequences of poor oral health in chronic kidney disease patients. Clinical journal of the American Society of Nephrology : CJASN. 2011;6(1):218-26. Epub 2010/12/01.

14. 14.C. P. Bots HSB, J. H. G. Poorterman, B. M. van Amerongen, M. Valentijn-Benz, E. C. I. Veerman, , PMtWaAVNA. Oral and salivary changes in patients with end stage renal disease (ESRD): a two year follow-up study. British Dental Journal 2007;202: E7.

15. 15.Renata Cristina Canuto Reisa JAB, Tatiana Miranda Deliberadorb „Ana Tereza Bittencourt Guimarãesc AFG, João Cézar Zielakb. Oral manifestations in chronic kidney failure patients. Revista Odonto Ciência Journal of Dental Science. 2016.

16. 16.Alba Jover Cerveró 1 JVB, Yolanda Jiménez Soriano , Rafael Poveda Roda . Dental management in renal failure: Patients on dialysis. Med Oral Patol Oral Cir Bucal 2008 Jul 1;13(7):E419-26. 2008.

17. 17.Divya PanDya1 aKn, K.S ravi3. Assessment and Correlation of Urea and Creatinine Levels in Saliva and Serum of Patients with Chronic Kidney Disease, Diabetes and Hypertension- A Research Study. Journal of Clinical and Diagnostic Research. 2016;2016 Oct, Vol-10(10): ZC58- ZC62.

18. 18.Judith T. Klassen B, MD, FRCPC , Brenda M. Krasko D. The Dental Health Status of Dialysis Patients. Janvier 2002, Vol 68, № 1 Journal de l'Association dentaire canadienn. 